Estudios Constitucionales, Año 11, No 1, 2013, pp. 459 - 476.

ISSN 0718-0195

Centro de Estudios Constitucionales de Chile Universidad de Talca

"Los jueces y la resolución de antinomias desde la perspectiva de las fuentes del derecho constitucional chileno"

Miriam Lorena Henríquez Viñas

\title{
LOS JUECES Y LA RESOLUCIÓN DE ANTINOMIAS DESDE LA PERSPECTIVA DE LAS FUENTES DEL DERECHO CONSTITUCIONAL CHILENO*
}

\author{
THE JUDGES AND THE RESOLUTION OF ANTINOMIES FROM THE PERSPECTIVE \\ OF THE SOURCES OF THE CHILEAN CONSTITUTIONAL LAW
}

\author{
Miriam Lorena HenríqueZ Viñas* \\ Profesora Derecho Constitucional \\ Universidad Alberto Hurtado \\ mhenriqu@uahurtado.cl
}

RESUMEN: Los jueces deben definir cuáles son las normas aplicables al caso que han de decidir. En muchas ocasiones los jueces -en el ejercicio de la función jurisdiccional ordinaria y constitucionaldeben resolver antinomias o conflictos normativos. Se hace entonces necesario que los jueces consideren los criterios y metacriterios para la resolución de las antinomias. En este contexto, el presente trabajo analizará los criterios y metacriterios clásicos: jerárquico, cronológico y de especialidad, cuyo examen se realizará desde la perspectiva de las Fuentes del Derecho Constitucional chileno.

ABSTRACT: The judges must define which are the procedure applicable to the case that they have to decide. In many occasions the judges -in the exercise of the jurisdictional ordinary and constitutional function- must solve antinomies or normative conflicts. In this context, the present work will analyze the criteria and metacriterios classic: hierarchic, chronological and of speciality, which examination will be realized from the perspective of the Sources of the Chilean Constitutional law.

PALABRAS CLAVE: Antinomias. Conflictos normativos. Criterios de resolución. Jerárquico. Cronológico. Especialidad. Fuentes del Derecho Constitucional.

KEY WORDS: Antinomies. Normative Conflicts. Criteria of resolution. Hierarchic. Chronological. Speciality. Sources of the Constitutional Law.

\section{INTRODUCCIÓN}

Los jueces deben definir cuáles son las normas aplicables al caso que han de decidir. En este ejercicio pueden enfrentarse a dos situaciones: a) el Derecho

\footnotetext{
* Trabajo recibido el 20 de marzo de 2012 y aprobado el 10 de octubre de 2012.

** Abogado, Universidad Nacional del Comahue (Argentina). Magíster en Derecho Público, Pontificia Universidad Católica de Chile (Chile). Doctor en Ciencias Jurídicas, Universidad de Santiago de Compostela (España). Profesora de Derecho Constitucional, Universidad Alberto Hurtado. mhenriqu@uahurtado.cl
} 
determina unívocamente qué debe hacer el juez; b) el Derecho no determina unívocamente qué debe hacer el juez. Esto último -siguiendo a Bulygin-puede ocurrir por tres motivos: 1) el Derecho no resuelve el caso genérico porque no hay ninguna norma que se refiera a ese caso (laguna normativa), 2) el Derecho resuelve el caso genérico de forma inconsistente, mediante dos o más normas incompatibles (antinomia), 3) aunque el caso genérico esté solucionado, no es posible subsumir el caso individual en ese caso genérico, debido a la vaguedad o textura abierta de los conceptos que caracterizan el caso genérico (laguna de reconocimiento $)^{1}$. A lo anterior puede agregarse la laguna axiológica, que se produce cuando el caso se encuentra formalmente solucionado en el sistema normativo, sin embargo a juicio del intérprete, tal solución no es satisfactoria y es conveniente incluir, suprimir o modificar alguna de las condiciones que el sistema acoge como relevantes ${ }^{2}$.

Como se advierte, los jueces deben decidir el derecho aplicable al caso concreto resolviendo -en muchas ocasiones- antinomias o conflictos normativos. Se hace entonces necesario que los jueces cuenten con elementos que les provean de soluciones para resolver tales conflictos. Justamente, el presente trabajo busca referirse a los criterios y metacriterios para la resolución de las antinomias. Lo anterior, desde la particular mirada de los jueces -ordinarios y constitucionales- $y$ de las Fuentes del Derecho Constitucional chileno.

Como adelanté, realizaré el presente estudio desde la posición que corresponde tomar al juez ante las antinomias, siendo mi principal interés señalar cómo el órgano jurisdiccional debe decidir cuál de las normas incompatibles debe aplicar en el caso concreto con preferencia a otra, pues no puede aplicar ambas. Además, el análisis propuesto desde la perspectiva de las Fuentes del Derecho Constitucional Chileno se justifica en que la Constitución es: a) la norma fundante del ordenamiento jurídico; b) determina el ámbito de vigencia y validez de las normas del ordenamiento jurídico, las que deben sujetarse tanto formal como materialmente a ella; c) regula las formas de producción de las demás normas jurídicas; d) define el Sistema de Fuentes, precisando los órganos competentes para la producción de las normas jurídicas, como las categorías básicas a través de las cuales se manifiesta

\footnotetext{
1 BulYgin (2006), pp. 104-105.
}

2 Según Bulygin la laguna axiológica se produce cuando las valoraciones del juez no coinciden con las del legislador, sea porque haya alguna circunstancia, relevante en la opinión del juez, que no ha sido contemplada por la norma general, sea porque haya un conflicto valorativo directo entre el juez y la norma del legislador. BuLYGin (2009), p. 89. 
la voluntad de dichos órganos y las relaciones entre las mismas por razón de su jerarquía o de su competencia.

Para la consecución del objetivo planteado es que seguiré el siguiente recorrido: a) Definiré las antinomias, señalaré los casos en que se producen y distinguiré algunos de sus tipos; b) Luego, revisaré los criterios clásicos de resolución de antinomias, tales como el criterio jerárquico, cronológico y de especialidad. No trataré deliberadamente en este trabajo el criterio de competencia, el que por sus particularidades, merece un tratamiento diferenciado; c) Finalmente, me referiré a la insuficiencia de los criterios analizados.

\section{Definición y ClaSES DE ANTINOMIAS}

Como es sabido, la doctrina ha debatido arduamente sobre la existencia de conflictos normativos en el orden jurídico, discutiendo en definitiva sobre el carácter coherente o consistente del mismo. Sin embargo, en el contexto de este trabajo parto del supuesto que los conflictos normativos son inevitables en un ordenamiento jurídico por razón de su dinamismo y la diversidad de poderes normativos que coexisten en los ordenamientos complejos.

El concepto de conflicto normativo dista de ser claro. Sin embargo, la definición que seguiré en este trabajo es la de Huerta Ochoa, quien sostiene que el conflicto normativo es aquel que se presenta cuando dos o más normas son formal o materialmente incompatibles ${ }^{3}$.

Precisando la distinción entre incompatibilidad formal y material se habla de "infracción" cuando la incompatibilidad en comento sea formal, es decir, cuando no se hayan cumplido debidamente las normas procedimentales o existan vicios de competencia. Si, por el contrario, la incompatibilidad normativa es material corresponde hablar de "contradicción normativa", lo que generalmente se produce por contradicción en el carácter de la norma (contradicción deóntica) o en su contenido (contradicción lógica) ${ }^{4}$. Constituyen ejemplos de contradicción deóntica los casos en que: a) una norma manda a hacer alguna cosa y una norma prohíbe hacer esa misma cosa, b) una norma manda hacer alguna cosa y otra permite no hacer esa misma cosa, c) una norma prohíbe hacer alguna cosa y otra permite hacer esa misma cosa.

\footnotetext{
${ }^{3}$ Huerta (2007), p. 52.

${ }^{4}$ Huerta (2007), pp. 52-58.
} 
Brevemente, los supuestos del conflicto normativo son, según Bobbio: a) la incompatibilidad entre dos normas; b) que las dos normas pertenezcan al mismo ordenamiento; c) que las dos normas tengan el mismo ámbito de validez 5 . En una norma pueden distinguirse cuatro ámbitos de validez: temporal, espacial, personal y material ${ }^{6}$.

Por otra parte, existen diferentes tipos de antinomia. Siguiendo la clásica la taxonomía propuesta por Alf Ross en su libro On Law and Justice, pueden distinguirse tres tipos de inconsistencias: a) Inconsistencia total-total, que se produce cuando en ningún caso una de las normas se puede aplicar sin generar conflicto con la otra. Si los hechos condicionales de cada norma son simbolizados por un círculo, una inconsistencia de esta clase ocurre cuando los dos círculos coinciden; b) Inconsistencia total-parcial, una de las dos normas no puede ser aplicada bajo ninguna circunstancia sin entrar en conflicto con la otra, mientras que la otra norma tiene un campo de aplicación que no está en desacuerdo con la primera. Tal inconsistencia se grafica con dos círculos, uno de los cuales está completamente dentro del otro; c) Inconsistencia parcial-parcial, cuando cada una de las normas tiene un campo de aplicación que entra en conflicto con el de la otra y a su vez un campo de aplicación dentro del cual el conflicto normativo no existe. Tal inconsistencia se expresa con dos círculos en intersección ${ }^{7}$.

Para una mejor comprensión de lo expresado, sugiero considerar los claros ejemplos propuestos por Nino: a) Inconsistencia total-total. Ejemplo: las dos normas. (N1): La importación de tractores debe pagar un recargo aduanero. (N2): La importación de tractores está exenta de recargos aduaneros; b) Inconsistencia total-parcial. Ejemplo las dos normas. (N1): La importación de vehículos debe pagar un recargo aduanero. (N2): La importación de tractores está exenta de recargos aduaneros; c) Inconsistencia parcial-parcial. Ejemplo: las dos normas. (N1): La importación de vehículos debe pagar un recargo aduanero. (N2): La importación de instrumentos para la producción agrícola está exenta de recargos aduaneros. En este último ejemplo, los tractores están en el campo de conflicto

\footnotetext{
${ }_{5}^{5}$ Una definición clásica que expone los supuestos del conflicto normativo es la propuesta por Norberto Bobbio, quien señala que la antinomia es aquella situación de incompatibilidad que se produce entre dos normas que pertenecen al mismo ordenamiento y tiene el mismo ámbito de validez, en virtud de la cual la aplicación de una de las normas conduce a resultados contrarios a los que se generan con la aplicación de la otra. BoвbIо (1987), p. 189.

${ }^{6}$ Bоввіо (1987), p. 188.

7 Ross (2004), pp. 128-129.
} 
de ambas normas, los autos sólo están comprendidos en la primera norma y los arados sólo se rigen por la segunda ${ }^{8}$.

Otra clasificación interesante es la que distingue entre antinomias aparentes y reales. Según Prieto Sanchís, una antinomia es aparente cuando encierra un problema de validez de alguna de las normas en conflicto, siendo una de ellas inválida. La antinomia es real cuando se entabla entre dos normas válidas del sistema. Las primeras -las antinomias aparentes- se producen en el nivel de la producción del Derecho; las reales en el plano de la aplicación?.

Expuestos brevemente el concepto y los tipos de antinomias -es decir, los parámetros para su determinación- corresponde pasar al estudio de los criterios que permitirán a los jueces resolverlas, decidiendo sobre la norma que debe ser conservada y aplicada al caso concreto y la que debe ser eliminada o inaplicada.

\section{CRITERIOS DE RESOlUCIÓN DE CONFLICTOS}

Para la solución de las antinomias o conflictos normativos los jueces se valen de ciertos criterios - preconstituidos o no- que evidencian que los sistemas jurídicos no son meros conjuntos de normas, sino conjuntos ordenados de ellas ${ }^{10}$.

Los criterios de resolución de antinomias pueden ser definidos -conforme a Chiassoni- como aquel tipo particular de metanormas metodológicas cuya función consiste en establecer: a) cuál, de entre dos normas incompatibles, debe prevalecer sobre otra; y además, b) de qué manera ésta debe prevalecer, esto es, con qué efectos desde el punto de vista del ordenamiento jurídico pertinente, o bien de un sector o subsector de aquél ${ }^{11}$.

Los criterios de resolución de antinomias pueden constar en normas explícitas, en normas implícitas, e incluso en normas consuetudinarias. En el caso de que no consten en normas expresas -ya constitucionales o de otro tipo- su adecuado

\footnotetext{
${ }^{8}$ Nino (2001), p. 275.
}

9 Prieto (2008), pp. 133-134.

Corresponde distinguir esta taxonomía de aquella propuesta por Bobbio y que alude a un criterio distinto. Bobbio sostiene que las antinomias solubles son aparentes y las insolubles son reales. En las antinomias reales el intérprete queda abandonado a sí mismo. Bоввıо (1987), p. 191.

${ }^{10}$ Los criterios preconstituidos son aquellos establecidos directamente en su contenido y prelación de uso por el Derecho positivo. Los criterios no preconstituidos son generados racionalmente por el intérprete.

${ }^{11}$ Chiassoni (2011), p. 319. 
uso y aplicación dependerá de que exista una elaborada Teoría sobre las Fuentes del Derecho y que la misma sea compartida por jueces y juristas.

$\mathrm{Al}$ estudio de dichos criterios aspira-como expresé previamente- el presente trabajo. Para ello distinguiré y abordaré los criterios clásicos de resolución de conflictos normativos: criterio jerárquico, cronológico y de especialidad.

\section{A. Criterio Jerárquico}

Comúnmente se define al criterio jerárquico como aquel según el cual la norma de rango superior, en caso de conflicto normativo, prevalece sobre la de rango inferior: lex superior derogat legi inferiori. Sin embargo, corresponde apuntar que no existe un único concepto en la doctrina-nacional o comparada- sobre el sentido que debe atribuirse a la noción de jerarquía normativa ${ }^{12}$.

Como se observa, la definición común presupone la previa determinación de la norma superior, lo que a su vez requiere la identificación de las relaciones jerárquicas entre las distintas Fuentes del Derecho. Empero, como se sabe, no siempre esto es posible ni pacífico. La tarea es algo más sencilla cuando el juez se encuentra frente a reglas explícitas que señalan las relaciones jerárquicas entre las distintas Fuentes del Derecho.

Son ejemplos de normas constitucionales que explicitan la supremacía jerárquica de la propia Constitución las siguientes: a) artículo 60 inciso primero: "Los órganos del Estado deben someter su acción a la Constitución y a las normas dictadas conforme a ella, y garantizar el orden institucional de la República"; b) artículo 32 No 1: "Son atribuciones especiales del Presidente de la República: 1. Concurrir a la formación de las leyes con arreglo a la Constitución, sancionarlas y promulgarlas"; c) el artículo 93 de la Constitución que dispone las atribuciones del Tribunal Constitucional en lo relativo al control de constitucionalidad de los

12 Guastini distingue no menos de cuatro tipos de jerarquías normativas: a) jerarquía estructural o formal; b) jerarquías materiales; c) jerarquías lógicas; d) jerarquías axiológicas. Guastini (1999), pp. 376-378. Ferrer también distingue cuatro sentidos en que podría decirse que una norma es jerárquicamente superior a otra: a) jerarquía estructural o formal, en la que las normas que regulan la producción de otras normas -las normas de competencia- son jerárquicamente superiores a las normas que se dictan en ejercicio de esa competencia; b) jerarquía material, en virtud de la cual una norma es superior jerárquicamente a otra cuando, en caso de conflicto, la primera prevalece sobre la segunda. Este segundo tipo de jerarquía requiere un conflicto lógico entre los contenidos de las normas en cuestión; c) jerarquía lógica, que sostiene que una norma es superior a otra cuando la primera versa sobre la segunda. Este tercer tipo presupone la existencia de diversos niveles de lenguaje en el discurso normativo; e) jerarquía axiológica, se da cuando el intérprete atribuye un valor superior a una de ellas respecto de la otra. Ferrer y Rodríguez (2001), pp. 136-140. 
distintos tipos de ley, los decretos con fuerza de ley, los tratados internacionales, los reglamentos autónomos, los reglamentos de ejecución, los autos acordados, entre otras fuentes; d) artículo 99 inciso segundo: "Corresponderá, asimismo, al Contralor General de la República tomar razón de los Decretos con Fuerza de Ley, debiendo representarlos cuando ellos excedan o contravengan la ley delegatoria o sean contrarios a la Constitución"; e) las disposiciones previstas en el capítulo XV de la Constitución que trata sobre la reforma constitucional y en la que se da cuenta que la Carta Fundamental no podrá ser modificada por cualquier ley.

De los ejemplos reseñados puede observarse que las referencias explícitas que hace la propia Constitución sobre su supremacía se distinguen en base a: a) la exigencia de conformidad del ordenamiento jurídico a ella; b) las garantías directas de su supremacía, a través del control normativo que realizan órganos como el Tribunal Constitucional y la Contraloría General de la República; c) las garantías indirectas, como la imposibilidad de que sea modificada por cualquier ley.

Constituyen un par de ejemplos de referencia expresa de la superioridad jerárquica de la ley respecto de la potestad reglamentaria de ejecución, las siguientes disposiciones constitucionales: a) artículo 32 No 6 "Son atribuciones especiales del Presidente de la República: $6^{\circ}$. Ejercer la potestad reglamentaria en todas aquellas materias que no sean propias del dominio legal, sin perjuicio de la facultad de dictar los demás reglamentos, decretos e instrucciones que crea convenientes para la ejecución de las leyes", b) artículo 98: “Un organismo autónomo con el nombre de Contraloría General de la República ejercerá el control de la legalidad de los actos de la Administración (...)”.

Otro ejemplo de norma constitucional que explicita la igual jerarquía normativa entre el decreto con fuerza de ley y la ley es el contenido en el artículo 64 inciso séptimo que dispone: "Los decretos con fuerza de ley estarán sometidos en cuanto a su publicación, vigencia y efectos, a las mismas normas que rigen para la ley".

Sin embargo, hay casos en que las relaciones jerárquicas entre las normas no se hallan en disposiciones expresas. Surge, entonces, la necesidad de identificar las normas implícitas o consuetudinarias que dan base para ordenarlas jerárquicamente. La doctrina ha esgrimido distintas razones para determinar cuándo se está ante una relación jerárquica entre normas. Algunas de las soluciones que se han propuesto son: a) la aplicabilidad de la norma superior en caso de conflicto, b) de la capacidad derogatoria, c) de la referencia al órgano creador de la norma, d) de la fundamentación material o formal de la validez, e) de la posibilidad de 
fiscalización judicial, f) del deber de acatamiento de la norma inferior respecto de la norma superior ${ }^{13}$, entre otras. La misma doctrina ha cuestionado la suficiencia de cada uno de estos criterios.

En nuestro medio parece existir un consenso en la doctrina y en la jurisprudencia sobre la siguiente relación jerárquica entre las Fuentes del Derecho Constitucional chileno: a) La Constitución es la norma suprema; b) La ley y el reglamento autónomo son infraconstitucionales; c) La ley es superior a las normas emanadas de la potestad reglamentaria de ejecución; d) La ley tiene igual jerarquía que el decreto con fuerza de ley ${ }^{14}$. No existe acuerdo -ni doctrinal ni jurisprudencial-sobre la jerarquía de los tratados internacionales ${ }^{15}$. Además, cierta parte de la doctrina-que no comparto- sostiene que existe una relación jerárquica entre los distintos tipos de ley ${ }^{16}$.

El criterio jerárquico resuelve antinomias aparentes. En consecuencia, la aplicación del mismo importa la invalidez de una de las normas en conflicto -en este caso de la norma inferior que contradice la superior-y no su pérdida de vigencia, por tanto, el efecto no será la derogación. La norma inferior no debe ser aplicada porque no es válida.

Sin perjuicio de las precisiones apuntadas, corresponde afirmar que cada ordenamiento jurídico puede disponer sobre el régimen de invalidación de las normas y el régimen de eficacia de los actos declarativos de esa invalidez ${ }^{17}$. Esto es, quién tiene competencia para enjuiciar la validez de una norma y las condiciones en que se ejerce esa competencia -régimen de invalidación-y los efectos jurídicos

13 Ruiz Miguel (1988), p. 141.

${ }^{14}$ En un sentido coincidente, CORDERO (2009), pp. 38-41.

15 Puede identificarse la disparidad de opiniones sobre la jerarquía de los tratados internacionales, en general y de derechos humanos en particular en Henríquez (2008), pp. 73-119 y NogueIRA (1996), pp. 341-380.

16 Quienes sostienen que la relación entre los distintos tipos de ley es de jerarquía normativa se basan en la mayor exigencia de la Constitución en materia de quórum para su aprobación, modificación y derogación. En este sentido, por ejemplo, Lautaro Ríos Álvarez y Enrique Silva Cimma. El primero expresa: "En resumen, son menos que la Constitución, pero más que las de quórum calificado (...) y que las leyes ordinarias”, refiriéndose a las leyes orgánicas constitucionales. Ríos (1983), p. 41. Por su parte, Silva Cimma expresa: "En todo caso, la distinta naturaleza de cada una de las Fuentes examinadas, marca a su vez la jerarquía y orden de prelación entre ellas, de modo que su estructura piramidal será, después de la Constitución Política, la Ley Interpretativa de la Constitución, la Ley Orgánica Constitucional; la Ley de Quórum Calificado y, cerrando el estamento de los actos legislativos; la Ley Común u Ordinaria”. SiLvA Cimma (1992), p. 106.

17 Gascón (1997), p. 137. 
que se atribuyen a los actos declarativos de invalidez -régimen de eficacia-, esto es efectos ex tunc o ex nunc, generales o particulares.

En nuestro sistema, el juez ordinario ante un conflicto normativo entre normas de distinta jerarquía deberá preterir la aplicación de la norma inválida al caso concreto, pero no podrá declarar su invalidez. De conformidad con la Constitución -artículos 93 y 94- la invalidez de una norma vigente sólo puede ser declarada por el Tribunal Constitucional. Sin embargo -como dice Núñez Leiva- la coherencia del sistema no puede soslayar los efectos que se derivan de tales opciones ${ }^{18}$.

Para finalizar este apartado, propongo un ejemplo ficticio para una mejor comprensión sobre cómo opera el criterio jerárquico: N1, norma legal señala: "La importación de tractores debe pagar un recargo aduanero". N2, norma reglamentaria, dispone: "La importación de tractores está exenta de recargos aduaneros". El juez ante tal inconsistencia total -total y deóntica- pues una norma prohíbe y a otra permite -deberá resolver empleando lo dispuesto por la norma superior, es decir la norma legal N1, siendo la norma reglamentaria "ilegal" y por tanto inválida.

\section{B. El criterio cronológico}

El criterio cronológico es aquel según el cual la norma posterior en el tiempo, en caso de conflicto normativo, prevalece sobre la anterior: lex posterior derogat legi priori.

Este criterio se aplica para resolver verdaderos conflictos diacrónicos entre normas válidas y de igual jerarquía, pero tiene dos limitaciones: a) ha de predicarse respecto de normas comunes, en otro caso la eficacia derogatoria de la norma posterior puede corregirse mediante la aplicación de la excepción del criterio de especialidad; b) sólo se puede aplicar respecto de normas homogéneas, o sea, que pertenezcan al mismo ámbito de competencia ${ }^{19}$.

El efecto de la aplicación del criterio cronológico es la derogación de la norma anterior.

La Constitución Política no alude expresamente al criterio cronológico como criterio de resolución de antinomias, tan sólo se refiere a su efecto -la derogaciónen el artículo 94 al establecer el efecto de la sentencia del Tribunal Constitucional que declara la inconstitucionalidad de un precepto legal, cuando señala que: "No

18 NúÑEZ (2011), p. 88.

19 Henríquez (2009), p. 14. 
obstante, el precepto declarado inconstitucional en conformidad a lo dispuesto en los numerales 2, 4 ó 7 del artículo 93, se entenderá derogado desde la publicación en el Diario Oficial de la sentencia que acoja el reclamo, la que no producirá efecto retroactivo".

En nuestro sistema es el Código Civil el que se refiere explícitamente al criterio cronológico en sus artículos 52 y 53, puntualmente el inciso tercero del artículo 52 que dispone respecto de la derogación: "Es tácita, cuando la nueva ley contiene disposiciones que no pueden conciliarse con las de la ley anterior". Por otro lado, rige en Chile desde 1861 la conocida ley "Sobre el efecto retroactivo de las leyes", la que anuncia ya en su artículo $1^{\circ}$ que reglará la aplicación de las leyes promulgadas en distintos tiempos, cuando señala: "Los conflictos que resultaren de la aplicación de leyes dictadas en diversas épocas se decidirán con arreglo a las disposiciones de la presente ley". Como dice Barros, las características de esta ley son: a) da soluciones para diversos tipos de materias, siendo principalmente una guía práctica; $b$ ) tiene carácter supletorio; c) trata más bien el efecto "no retroactivo" que "retroactivo" de las leyes ${ }^{20}$. Esta ley brinda soluciones particulares según la materia, pero en general confirma que la nueva ley deroga la anterior. Por ejemplo, en su artículo $2^{\circ}$, dispone: "Las leyes que establecieren para la adquisición de un estado civil, condiciones diferentes de las que exigía una ley anterior, prevalecerán sobre ésta desde la fecha en que comiencen a regir".

Respecto del efecto de la aplicación del criterio cronológico -la referida derogación- formularé una serie de afirmaciones: a) La derogación está relacionada con la vigencia de la norma y no con su validez; b) La derogación es un fenómeno perfectamente regular, cuyo fundamento es responder al cambio en el sistema jurídico. A lo dicho, agregaré que el efecto es la derogación "tácita" de la norma anterior, quedando, por ende, excluidas de este análisis las derogaciones expresa, implícita y orgánica.

La derogación tácita requiere ser declarada. Tal declaración -que generalmente emana de un órgano jurisdiccional o un órgano aplicador del Derecho-importa un acto de interpretación al caso particular.

El profesor chileno, Antonio Bascuñán, confirma que la derogación que se produce por la aplicación del criterio cronológico es la derogación tácita. A su juicio, la derogación tácita se produce cuando el órgano que debe resolver un caso, y debe fundar su decisión sujetándose al derecho vigente, constata

${ }^{20}$ Barros (1995), p. 7. 
que éste contiene dos soluciones distintas para ese caso, incompatibles entre sí. En opinión del mismo autor, la derogación tácita de la ley anterior no es el efecto de un acto realizado en ejercicio de una potestad normativa, sino los efectos de un complejo de reglas que gobiernan el ejercicio de la potestad jurisdiccional. Estas reglas obligan al órgano adjudicador a seleccionar de una manera determinada la norma aplicable al caso. Por tal motivo, la derogación tácita de la ley anterior es constatada y declarada por el tribunal en la fundamentación de su sentencia. Por eso supone un acto interpretativo de la norma anterior y la posterior, que identifique sus respectivos sentidos y constate su incompatibilidad entre $\mathbf{s i}^{21}$.

Nuevamente propongo un ejemplo ficticio para una sencilla comprensión de lo reseñado: N1, norma legal posterior, señala: "La importación de tractores debe pagar un recargo aduanero". Por su parte, N2, norma legal anterior, dispone: "La importación de tractores está exenta de recargos aduaneros". El juez ante tal inconsistencia total-total, deóntica, entre normas de igual jerarquía, deberá aplicar la norma posterior, es decir, N1.

Otro ejemplo: N1, norma legal posterior, señala: "La importación de vehículos debe pagar un recargo aduanero". Por su parte, N2, norma legal anterior, dispone: "La importación de instrumentos para la producción agrícola está exenta de recargos aduaneros". El juez ante tal inconsistencia parcial-parcial, entre normas de igual jerarquía, deberá aplicar la norma posterior, es decir, N1.

La aplicación del criterio cronológico no procede cuando la inconsistencia es total-parcial. En este supuesto procede la aplicación del criterio de especialidad. Por ejemplo: N1, norma legal anterior, señala: "La importación de tractores está exenta de recargos aduaneros" N2, norma legal posterior, dispone: "La importación de vehículos debe pagar un recargo aduanero". El juez ante la referida inconsistencia deberá, en primer término, establecer si existe una relación de género a especie entre ambas normas. En este ejemplo, la norma $\mathrm{N} 1$ es especial respecto de la norma N2 que es general. En consecuencia, el juez deberá aplicar la norma $\mathrm{N} 1$, a pesar de ser anterior. En conclusión, el criterio cronológico cede ante el criterio de especialidad cuando la inconsistencia es total-parcial.

Un caso más complejo es el siguiente: el conflicto se produce entre normas de la misma jerarquía cuya fecha de entrada en vigencia coincide. Por ejemplo, el caso de normas que forman parte de un Código y son incompatibles entre sí. Este es

${ }^{21}$ Bascuñán Rodríguez (2000), p. 238. 
un supuesto en que los criterios de resolución de conflictos resultan insuficientes, pues se trata de normas de igual jerarquía y coetáneas, no pudiendo aplicarse ni el criterio jerárquico ni el cronológico ${ }^{22}$. Las alternativas de solución que propone Kelsen para este supuesto son dos: a) mediante una interpretación en el sentido de que el órgano encargado de la aplicación de la ley puede escoger entre las dos normas, es decir, que la ley autorizaría al órgano a aplicar en un caso concreto la una $o$ la otra, no la una $y$ la otra; b) si esta interpretación no es posible, las dos normas se derogan entre $s^{i 23}$.

\section{El criterio de especialidad}

El criterio de especialidad es aquel que opera cuando se produce un conflicto normativo entre una norma general y otra especial respecto de aquélla, que se resuelve mediante la aplicación preferente de la norma especial: lex specialis derogat generali.

El sentido del criterio de especialidad es hacer posible la aplicación de normativas singulares a grupos sociales diferenciados, permitir que determinados sectores no se rijan por el patrón general, habilitándoles una regulación específica que se adapte en mayor medida a sus necesidades. Como expresa Bobbio: "El paso de una regla más amplia (que abarca cierto genus) a una regla derogatoria menos amplia (que abarca una species del genus) corresponde a una exigencia fundamental de justicia, entendida como igual tratamiento a las personas que pertenecen a una misma categoría" ${ }^{24}$.

En nuestro sistema la referencia al criterio de especialidad tampoco se encuentra prevista en la Constitución, sino en el artículo 13 del Código Civil que señala: "Las disposiciones de una ley, relativas a cosas o negocios particulares, prevalecerán sobre las disposiciones generales de la misma ley, cuando entre las unas y las otras hubiere oposición".

Este criterio ostenta las siguientes particularidades: a) hace referencia a la existencia de conflicto normativo por razón de la materia, b) tiene siempre un carácter relativo que implica la comprobación del contenido de una norma con otra a través de una actividad interpretativa ${ }^{25}$, c) sólo puede ser aplicable a antinomias total-parcial, d) resuelve antinomias reales, porque ambas normas en conflicto son válidas.

\footnotetext{
22 García Maynez (2004), pp. 49-50.

${ }^{23}$ Kelsen (2009), p. 42.

${ }^{24}$ Bobbio (1987), p. 195.

25 Henríquez (2009), p. 15.
} 
Por otra parte -como apunta Chiassoni- la aplicación del criterio de especialidad es pacífica en lo que concierne a las antinomias entre normas que son: a) coetáneas y b) pertenecientes a la misma fuente ${ }^{26}$. Sin embargo, cuando no se trata de estos casos, la aplicación del criterio de especialidad interfiere con el criterio cronológico y el jerárquico, como se verá en el apartado final.

Cuando se aplica el criterio de especialidad no se invalida la norma general, tampoco se la deroga totalmente. La aplicación de este criterio importa la derogación sólo de aquella parte de la norma general que es incompatible con la norma especial. Como expresa Bobbio: "Por efecto de la ley especial, la ley general pierde vigencia parcialmente" 27 .

Planteo nuevamente un ejemplo simulado de lo expuesto: N1, norma especial, señala: "La importación de tractores está exenta de recargos aduaneros". N2, norma general, dispone: "La importación de vehículos debe pagar un recargo aduanero". El juez deberá interpretar de forma restrictiva una de las normas (la especial) respecto de la otra (la general), aplicando la especial, en este caso N1.

Otro ejemplo, aunque más complejo: el conflicto se produce entre normas de la misma jerarquía, contemporáneas, ambas generales, por ejemplo, dos normas generales incompatibles contempladas en un Código. Este es un supuesto en que los criterios de resolución de conflictos resultan insuficientes, pues es no posible aplicar el criterio jerárquico, cronológico ni de especialidad. Sobre la insuficiencia de los criterios explicados versará brevemente la última parte de este trabajo.

\section{LA INSUFICIENCIA DE LOS CRITERIOS}

Los criterios antes analizados si bien son útiles para la resolución de las antinomias, no sirven para resolver todos los casos posibles, tanto así que Bobbio distingue entre antinomias solubles e insolubles ${ }^{28}$. Las razones por las cuales no todas las antinomias son solubles se deben a que: a) hay casos de antinomias a las cuales no se les puede aplicar ninguna regla ideada para la solución de antinomias, b) hay casos en los cuales se pueden aplicar al mismo tiempo dos o más reglas opuestas entre $s^{29}$. Esto último da origen a los conflictos de segundo

\footnotetext{
26 Chiassoni (2011), p. 325.

27 Bobbio (1987), p. 196.

28 Bobbio (1987), p. 191.

29 Boвbio (1987), p. 191.
} 
grado, que ya no se producen entre normas sino entre los criterios de solución de antinomias.

Algunos de los conflictos de segundo grado que pueden sucederse son: a) entre el criterio jerárquico y el cronológico; b) entre el criterio de especialidad y el cronológico; c) entre el jerárquico y el de especialidad. En este apartado dejaré planteadas más preguntas que respuestas, con la expectativa de desarrollar este acápite en un próximo trabajo.

El conflicto entre el criterio jerárquico y el cronológico se produce cuando una norma anterior-superior es incompatible con otra norma posterior-inferior. Si se aplica el criterio jerárquico prevalece la primera. Si se aplica el criterio cronológico prevalece la segunda. ¿Cuál de los dos criterios prevalece sobre el otro? ¿El jerárquico o el cronológico? En general se acepta que en casos como el planteado el criterio jerárquico prevalece sobre el cronológico.

Por su parte, el conflicto entre el criterio de especialidad y el cronológico sucede entre una norma anterior-especial incompatible con una norma posteriorgeneral. Existe conflicto porque al aplicar el criterio de especialidad se da prevalencia a la primera norma, y al aplicar el criterio cronológico se da prevalencia a la segunda. Previamente, hemos señalado que la ley posterior general no deroga la ley anterior especial, conforme a tal afirmación todo indica que el conflicto entre el criterio de especialidad y el criterio cronológico se resuelve a favor del primero $^{30}$. Sin embargo, esta afirmación debe ser considerada con cautela a la luz de la casuística.

Finalmente, el conflicto entre el jerárquico y el de especialidad se da entre una norma superior-general incompatible con una norma inferior-especial. Si se aplica el criterio jerárquico prevalece la primera y si se aplica el criterio de especialidad prevalece la segunda. ¿Cuál de los dos criterios es aplicable? Bobbio dice al respecto: "No existe una regla general consolidada"

Mendonca y Guibourg sostienen que es habitual, aunque no uniforme, considerar prevaleciente el criterio jerárquico. Por otro lado, afirman que el criterio cronológico cede siempre ante el jerárquico y en ocasiones antes el de especialidad. El criterio jerárquico no cede ante el cronológico, pero su supremacía no se impone necesariamente ante el de especialidad ${ }^{32}$.

\footnotetext{
30 Boвbio (1987) p. 203.

31 Boвbio (1987) p. 204.

32 Mendonca y Guibourg (2004), p. 131.
} 


\section{CONCLUSIONES}

Los jueces deben decidir el derecho aplicable al caso concreto resolviendo -en muchas ocasiones- antinomias o conflictos normativos. Se hace entonces necesario que los jueces cuenten con elementos que les provean de soluciones para resolver tales conflictos.

Para la solución de las antinomias o conflictos normativos los jueces se valen de ciertos criterios que evidencian que los sistemas jurídicos no son meros conjuntos de normas, sino conjuntos ordenados de ellas. Los criterios de resolución de antinomias clásicos son: jerárquico, cronológico y de especialidad.

En relación con el criterio jerárquico, la Constitución establece -mediante referencias explícitas en su articulado- su supremacía jerárquica respecto de las demás fuentes del Derecho. Por otro lado, apoyados en la Carta Fundamental, la doctrina y la jurisprudencia mayoritaria consideran que: a) La ley y el reglamento autónomo son infraconstitucionales; b) La ley es superior a las normas emanadas de la potestad reglamentaria de ejecución; c) La ley tiene igual jerarquía que el decreto con fuerza de ley. Empero, no existe acuerdo -ni doctrinal ni jurisprudencial- sobre la jerarquía de los tratados internacionales. Por otro lado, aún se discute en nuestro medio si existe entre los distintos tipos de leyes una relación jerárquica o una vinculación competencial.

El criterio jerárquico resuelve antinomias aparentes. En consecuencia, la aplicación del mismo importa la invalidez de una de las normas en conflicto: la norma inferior incompatible con la norma superior no debe ser aplicada porque no es válida.

Por otra parte, el criterio cronológico se aplica para resolver verdaderos conflictos diacrónicos entre normas válidas. El efecto de la aplicación del criterio cronológico es la derogación tácita de la norma anterior. La Constitución Política no alude expresamente al criterio cronológico como criterio de resolución de antinomias, tan sólo se refiere a su efecto -la derogación- en el artículo 94 al establecer el efecto de la sentencia del Tribunal Constitucional que declara la inconstitucionalidad de un precepto legal. En nuestro sistema es el Código Civil el que se refiere explícitamente a este criterio.

Por último, el criterio de especialidad no se encuentra previsto en la Constitución, sino en el Código Civil. Este criterio: a) hace referencia a la existencia de conflicto normativo por razón de la materia; b) tiene siempre un carácter relativo que implica la comprobación del contenido de una norma con otra a través de una actividad interpretativa: c) sólo puede ser aplicable a antinomias total-parcial: d) resuelve antinomias reales, porque ambas normas en conflicto son válidas. 
Cuando se aplica el criterio de especialidad no se invalida la norma general, tampoco se la deroga totalmente. La aplicación de este criterio importa la derogación sólo de aquella parte de la norma general que es incompatible con la norma especial.

Finalmente, corresponde concluir que los criterios analizados si bien son útiles para la resolución de las antinomias, no sirven para resolver todos los casos posibles.

\section{BiBLIOGRAFÍA CITADA}

Aguiló Regla, Josep (1992): "Derogación, rechazo y sistema jurídico", en Doxa (No 11), pp. 263-280.

Alchourrón, Carlos; BulYgin, Eugenio (1991): Análisis lógico y Derecho (Madrid, Centro de Estudios Constitucionales).

Barros Bourie, Enrique (1995): El Derecho. (Santiago, Universidad de Chile), pp. 1-12.

BASCUÑÁn RodrígueZ, Antonio (2000): "Sobre la distinción entre derogación expresa y derogación tácita”, en Anuario de Filosofía Jurídica y Social. Derecho y Cambios Culturales (Vol. 18), pp. 227-261.

Boвbio, Norberto (1987): Teoría General del Derecho (Bogotá, Editorial Temis), pp. 269.

Bulygin, Eugenio (2006): El positivismo jurídico (México, Distribuciones Fontamara), pp. 165.

Bulygin, Eugenio; Mendonca, Daniel (2005): Normas y sistemas normativos (Madrid, Marcial Pons), pp. 95.

Bulygin, Eugenio (2009): "Mi visión de la filosofía del Derecho", en Doxa (No 32), pp. 85-90.

Chiassoni, Pierluigi (2011): Técnicas de interpretación jurídica (Madrid, Marcial Pons), pp. 366.

Cordero Quinzacara, Eduardo (2009). "Los principios y reglas que estructuran el ordenamiento jurídico chileno", en Revista Ius et Praxis (Vol. 15, № 2), pp. 11-49.

De Отто, Ignacio (2008): Derecho Constitucional. Sistema de Fuentes (Barcelona, Ariel), pp. 315.

Ferrer Beltrán, Jordi; Rodríguez, Luis (2001): Jerarquías normativas y dinámicas de los sistemas jurídicos (Madrid, Marcial Pons), pp. 218. 
García Maynez, Eduardo (2004): Introducción a la lógica jurídica (México, Colofón), pp. 228.

Gascón, Marina (1994): "Cuestiones sobre Derogación”, en Doxa (No 15-16), pp. 845-859.

GASCÓN, Marina (1997): "Sentido y alcance de algunas distinciones sobre la invalidez de las leyes", en Doxa (No 20), pp. 131-156.

GuASTINI, Riccardo (1999): Distinguiendo. Estudios de teoría y metateoría del Derecho (Barcelona, Gedisa), pp. 414.

Henríquez Viñas, Miriam (2008): "Jerarquía de los tratados de derechos humanos: análisis jurisprudencia desde el método de casos”, en Revista Estudios Constitucionales (Año 6, № 2), pp. 73-119.

Henríquez Viñas, Miriam (2009): Las Fuentes formales del Derecho (Santiago, LegalPublishing), pp. 114.

HenríqueZ Viñas, Miriam (2011): “¿Las normas derogadas pueden ser declaradas inaplicables por inconstitucionalidad? Comentario del fallo Roles Nos. 139909 y 1469-09 del Tribunal Constitucional", en Revista de Derecho Universidad Católica del Norte (Año 18, No 1), pp. 301-306.

Huerta OchoA, Carla (2003): "La acción de inconstitucionalidad como control abstracto de conflictos normativos", en Boletín Méxicano de Derecho Comparado (No 108), pp. 927-950.

Huerta OchOA, Carla (2007): Conflictos normativos (México, Instituto de Investigaciones Jurídicas UNAM), p. 263.

Kelsen, Hans (2009): Introducción a la Teoria Pura del Derecho (México, Ediciones Coyoacán), pp. 115.

Mendonca, Daniel; Guibourg, Ricardo (2004): La odisea constitucional. Constitución, teoría y método (Madrid, Marcial Pons), pp. 220.

Nino, Carlos Santiago (2001): Introducción al análisis del Derecho (Barcelona, Ariel), pp. 477.

Nogueira Alcalá, Humberto (1996): "Los Tratados Internacionales en el ordenamiento jurídico Chileno", en Revista Chilena de Derecho (Vol. 23, № 2 y 3), pp. 341-380.

NúN̄Ez LeIVA, José Ignacio (2011): La responsabilidad del Estado Legislador (Santiago, Librotecnia), pp. 147.

Prieto Sanchís, Luis (2008): Apuntes de Teoría del Derecho (Madrid, Trotta), pp. 331. 
Ríos Álvarez, Lautaro (1983): “Las leyes orgánicas constitucionales”, en Revista de Derecho (Vol. 10, № 1), pp. 39-44.

Ross, Alf (2004): On law and justice (New Jersey, The Lawbook Exchange), pp. 379.

Ruiz Miguel, Alfonso (1988): "El principio de jerarquía normativa”, en Revista Española de Derecho Constitucional (Año 8, No 24), pp. 135-154.

Ruiz SANZ, Mario (2002) Sistemas Jurídicos y conflictos normativos (Madrid, Dykinson), pp. 147.

Silva Cimma, Enrique (1992): Derecho Administrativo Chileno y Comparado. Introducción y Fuentes (Santiago, Editorial Jurídica de Chile), pp. 328. 